\title{
CECÍLIA MEIRELES, AUTORA DE LIVROS VOLTADOS AOS PEQUENOS LEITORES
}

Norma Seltzer Goldstein*

A produção de Cecília Meireles para crianças abrange várias obras, a maioria delas pouco conhecida ou divulgada.

Creio que a primeira reflexão deve deter-se no público leitor, imaginando-se o que uma educadora-poetisa teria a lhe dizer. É evidente a preocupação com a formação desse público, sendo perceptível em todos os textos a intenção de que tenham um papel formador, em sentido amplo, privilegiando-se valores como ética e solidariedade. Paralelamente, a poetisa deixa transparecer seu estilo, ora com maior ora com menor evidência: leveza, vivacidade, efeitos expressivos inusitados, tom poético. Essas características apontam para um texto bem elaborado cuja leitura causa prazer, dado importante quando se pensa em formação de leitores.

Alguns dos livros destinado a jovens leitores tornaram-se raros, outros ainda circulam. Mesmo que seja em bibliotecas ou acervos especiais, todo o conjunto merece uma visita. Este texto percorre essa produção, num total de sete livros, seguindo a ordem cronológica de sua publicação.

\section{Criança, meu amor...}

Trata-se de um conjunto de crônicas em prosa poética, ilustradas por Correia Dias. Foi adotado pela Diretoria Geral da instrução pública do Distrito Federal e aprovado pelo Conselho Superior de Ensino dos Estados de Minas Gerais e Pernambuco. Ou seja, teve a função de leitura complementar que hoje se atribui aos chamados livros "paradidáticos". A Editora Nova Fronteira o reeditou em 1977, seguindo-se algumas outras tiragens. Compõe-se de pouco mais de trinta crônicas. "Criança" abre a coletânea, dirigindo-se diretamente ao leitor e buscando sua cumplicidade:

\footnotetext{
* Universidade de São Paulo, FFLCH
} 
"Como te chamas? Que idade tens? Onde estás? Não sei. Não sei quem és, mas eu te amo". Sem te conhecer, compus este livro que te ofereço..." [Meireles, Cecília(1977). Criança, meu amor. São Paulo, Nova Fronteira, $4^{a}$ ed. p.9]

A temática abarca o contexto do universo infantil: retratos; momentos do dia; animais de estimação; tarefas; sentimentos; brincadeiras. Ao longo do livro, vem intercalada uma seqüência de mandamentos, no total de cinco. Trata-se de princípios a serem seguidos: amar a escola, respeitar a mestra e os colegas, ser sincero, aprender com os mais velhos. Estão redigidos em primeira pessoa verbal; ao lê-los, o leitor deve supor estar assumindo a palavra:

\footnotetext{
“A escola deu-me horas de alegria, sempre que me esforcei trabalhando.”[oc. p. 19]

"Durante o dia todo, a professora pensa em mim, pensa no que sou, pensa no que hei de ser." [ oc. p. 35]

“ Os que vieram antes de mim hão de me dar conselhos e hão de me citar exemplos." [ oc. p. 83]
}

Os mandamentos categorizam atitudes corretas ou incorretas, propondo valores que poderiam ser condensados numa só expressão: respeito ao próximo. Essa proposta perpassa todos os textos, evidenciando uma visão de mundo humanista. Intercalados entre as crônicas, os mandamentos diluem um pouco o seu caráter dogmático. Teria sido uma estratégia?

A escola brasileira mudou muito - como tudo o mais. Os mandamentos cecilianos podem, por isso, soar anacrônicos e ingênuos, sem que se perca a engenhosidade de sua criadora. É fundamental destacar-se a habilidade de escolher a primeira pessoa verbal, levando o leitor assumir os princípios como fossem dele, já que lhes empresta sua voz, para que ele se tornasse o enunciador. Ressalta, ainda, a valorização da escola e do professor, marcantes na formação do jovem. No final da primeira década do século XXI, talvez coubesse perguntar se não seria chegada a hora de recolocar na moda esses valores...

A crônica "Adelaide vai passear" flagra o instantâneo de duas garotinhas que se separam por dois meses. Dada a localização temporal, elas se tratam por "tu" como se percebe pelas desinências verbais:

- Quantos dias têm dois meses, Adelaide? Pensa lá!

- Sessenta dias...

- Não, meu amor, muito mais... Sessenta e dois. Porque vais passar lá longe os meses de julho e agosto...

As pessoas de que a gente gosta só deviam ficar distantes no mês de fevereiro...

E o mês de fevereiro ainda devia ser um pouquinho mais curto!... [ oc. p 27]

Note-se que a dor da ausência não é explicitada. Ela fica implícita, indiretamente, no comentário sobre o tamanho dos meses do ano e a duração da separação. 
Por vezes, o tom é solidariamente utópico:

A)

O meu pomar seria assim: todo aberto, para todos. E, quando o outono chegasse e as árvores ficassem cheias de frutos amarelos e vermelhos, nenhum pobrezinho teria fome, nenhuma criança choraria de sede, passando pelo meu pomar...

E, no inverno, ainda haveria lá lugar onde alguém se abrigasse, quando chovesse muito ou fizesse muito frio... [ o.c. p 53]

B)

O outono vai se acabando. E agora é o inverno que vem.

Não vês aquela neblina lá no horizonte? É dele... É o manto dele...

Quando o sentires mais perto, dize-lhe que seja piedoso, que não maltrate muito as criancinhas tuas irmãs, nas terras distantes, nas longes terras que não conheces e por onde ele vai passar! [ o.c. p 71/72]

Certas passagens encenam a importância das raízes:

A minha bonequinha Singu parece que pensa...

Eu tenho medo que ela, um dia, levante os bracinhos para mim e diga:

- Tens uma casa muito bonita e és muito boa... mas eu quero ir-me embora para lá onde as crianças se parecem comigo, as crianças de quimono e olhos oblíquos...

E eu terei de ficar sem ela... [ o.c. p 64/65]

Ao trabalhar essa crônica, os alunos poderiam questões como a diversidade cultural, as trocas entre culturas em contato e o preconceito entre grupos de costumes distintos.

Há três textos em versos: "Cantilena", "A canção dos tamanquinhos" e "Cantiga". O mesmo metro é empregado nos três textos, a redondilha maior, acentuando o caráter rítmico e lúdico dessas composições. A do meio assemelha-se a uma parlenda e as duas outras a cantigas de ninar. Teriam esses versos sido musicados? Não foi encontrado registro dessa informação, mas a hipótese parece plausível.

Em seu conjunto, as crônicas de Criança meu amor... associam valores éticos a cantos homenageando a vida, mesclando pitadas de tom didático e poético. Como atestam as reedições da Editora Moderna, cumprem até hoje o papel de 'leitura complementar". 
Em 1937, surgiu o volume Festa das Letras, em co-autoria com o médico Josué de Castro- relançado pela Nova Fronteira, em edição fac-similar, em 1996. Com ilustrações emoldurando todas as páginas, a obra apresenta um poema para cada letra do alfabeto. Texto e imagens orientam bons hábitos de higiene e alimentação. As quadrinhas louvam abacaxi e alface, no "A"; "escova de dentes" no "D"; "хuxu” no "X" e assim por diante.

O título sugeriria uma cartilha, recurso didático comum na época. Na verdade, trata-se de obra híbrida, possibilitando tanto atividades de língua portuguesa, quanto de ciências, no tópico relativo a nutrição. Cabe perguntar: estaria Cecília antecipando a hoje tão propalada interdisciplinaridade?

Conquanto explicitamente educativo, o livro não deixa de ter interesse poético, pois o leitor é envolvido pelo caráter lúdico dos jogos verbais. A finalidade de divulgar bons hábitos alimentares, revista pelo olhar contemporâneo, resulta datada e circunscrita a um período em que o consumo era muito diverso do atual. Mesmo assim, conserva encanto particular, graças ao suporte estilístico, de que se seguem alguns exemplos:

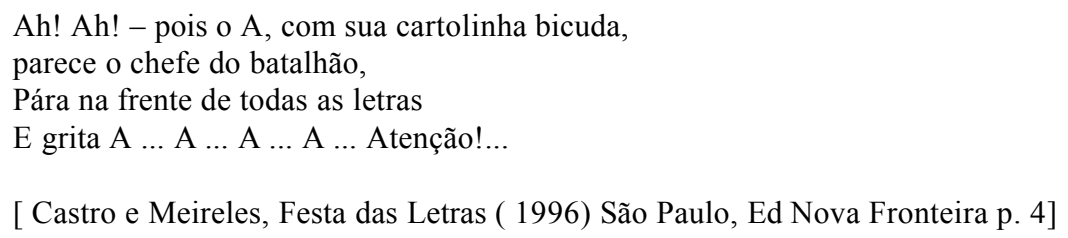

Note-se a exatidão da descrição, traduzindo o desenho e a posição da letra no alfabeto. O "A" personificado como comandante é seguido pelas demais letras que igualmente ganham vida:

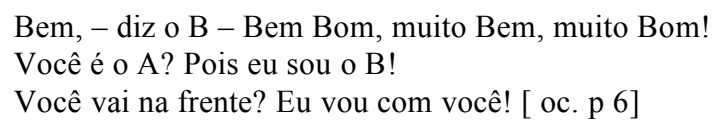

Ocorrem rimas, aliterações, assonâncias, personificações, paralelismos. O efeito rítmico aproxima-se do das parlendas e cantigas infantis, evidenciando a criatividade associada ao apelo pelos bons hábitos. O último poema, " $Z$ ", espelha o primeiro, retomando conclusivamente outras letras, numa festa em que essa letra dança em "ziguezague".

Hoje, A festa das letras apresenta sobretudo um interesse histórico, seja para conhecer melhor a autora, seja para avaliar a leitura nos anos 30. Ainda que ressalte a ação da educadora - que Cecília Meireles também foi -, ao leitor atento não escapa o caráter poético. 


\section{Rute e Alberto / Rute e Alberto resolveram ser turistas / Os passeios de tio Mário}

Em 1939, saiu pela Editora Globo o volume Rute e Alberto resolveram ser turistas. Seis anos mais tarde, em Boston, obra quase homônima foi editada por D.C. Heath, destinado ao ensino de língua portuguesa: Rute $\boldsymbol{e}$ Alberto. Talvez isso tenha ocorrido porque Cecília inaugurou o ensino de Português, na Universidade do Texas.

$\mathrm{Na}$ verdade, trata-se de uma única obra em três partes, sempre em torno da dupla central e de sua família, conforme cópia a que tive acesso ${ }^{1}$.

Poderíamos considerar o conjunto como um livro de ficção, pois prevalece o tom narrativo. D. Isabel e Dr. Silveira moram na Tijuca, com os filhos e duas empregadas. No verão, decidem alugar um apartamento na praia de Copacabana, para que todos desfrutem de "ar puro" e da brisa marinha.

Mais que a paisagem - avistada pela janela e comentada segundo diferentes enfoques- o cenário que prevalece é o universo familiar. Os dois irmãos têm disputas, mas respeitam-se mutuamente. E dialogam o tempo todo, entre si, com os pais, com as empregadas e com o tio, personagem que só aparece a partir da segunda parte.

Aliás, o título dessa parte corre o risco de soar enganoso a ouvidos contemporâneos. Diante dele, qualquer adolescente de 2001 imaginaria que os irmãos arrumaram suas mochilas e partiram para explorar o mundo. $\mathrm{Na}$ verdade, eles não viajam, mas decidem tornar-se turistas em sua própria terra. Expliquemos melhor, começando pela conceituação de "turista", apresentada pelo dr. Silveira: o estrangeiro que se detém diante de nossa paisagem com olhar atento, interessado, procurando observar bem aquilo que tem diante dos olhos. As crianças anunciam a todos que "decidiram ser turistas", isto é, que pretendem visitar o Rio de Janeiro, acompanhados pelo tio de São Paulo, procurando enxergar a própria cidade de modo a desvendar sua história e suas belezas, como fazem os turistas estrangeiros ou de outros pontos do país.

Anuncia-se que a obra conteria a matéria do programa de Ciências Sociais da terceira série do ensino fundamental, o que nos faz supor ter sido a convivência familiar retratada, de modo a permitir uma abordagem de tópicos da geografia e da História cariocas, capaz de motivar jovens leitores a se interessarem por sua cidade e a também se tornarem "turistas" nela.

O relato flui com leveza e as informações sobre o Rio apresentam-se diluídas com habilidade ao longo do texto. Não faltam, aqui e ali, pinceladas de saúde e higiene, também, incluindo um capítulo denominado "História das vitaminas". O que mais ressalta, no entanto, é o retrato da família. Um clima de respeito perpassa todas as cenas, as crianças interessam-se por pequenas coisas, fazem perguntas ao pai e à mãe, trocam idéias entre si, de um modo que nos parece, hoje, difícil de encontrar. Onde

\footnotetext{
${ }^{1}$ Cópia cedida pela pesquisadora Ana Maria de Oliveira, da UNESP de Assis, especialista em Cecília Meireles.
} 
encontrar, no século XXI, pais tão disponíveis? Crianças tão educadas e interessadas no próximo?

Seguem-se algumas passagens, a título de exemplificação:

Alberto e Rute conversam com a cozinheira Georgina sobre a primeira noite no apartamento de Copacabana. Eles tinham dormido bem, e ela?

- Pois eu, disse Georgina, foi uma luta para dormir... Fiquei escutando o mar, tchá... tchá... - toda a noite! Ele não dorme, não. O mar nunca dorme. É uma espécie de coisa encantada. Eu tenho um medo... Ih! ( oc. p 46)

O pai conta aos filhos sobre a viagem de Cabral, lendo trechos da carta de Caminha:

O Dr. Silveira explicou que os documentos antigos não eram fáceis de ler, porque a caligrafia e a ortografia eram bem diferentes das atuais, mas que certas pessoas se dedicavam a esses estudos... [ o.c. p 136]

Dessa forma, além de comentar a História da cidade e do país, o sábio pai também esboça pinceladas de História da Língua e de Filologia...

Alberto diz à mãe que resolveu ser turista e ela lhe pede para explicar o sentido dessa palavra. A resposta dele tem marcas da linguagem falada e do registro coloquial da língua, como se esperaria de um garoto:

- Papai disse que os turistas são pessoas que andam pelo mundo visitando lugares bonitos, vendo montanhas, praias, florestas, todas as coisas interessantes da natureza, - e também certos palácios, igrejas, museus- uma porção de coisas que não me lembro bem. Disse que os países que têm assim lugares e edifícios muito bonitos são visitados por estrangeiros que querem conhecer essas coisas e que isso é ótimo ...

O garoto completa, indicando seu desejo:

- Eu quero é ver essas coisas bonitas que os turistas vieram ver aqui. Pois você não acha, mamãe, que é mais fácil a gente ser turista estando aqui, do que vindo de longe? /.../ Papai disse que o Rio é uma cidade maravilhosa para o turismo. Que tem uma porção de coisas lindíssimas para se ver /.../

- Em todos esses lugares vocês já estiveram... - disse Dona Isabel, mas não prestaram muita atenção...

- É que naquele tempo nós não éramos turistas... - disse Alberto com importância. [oc. p 109] 
No final de dezembro, chega o natal. Os presentes destinados às crianças vêm com as seguintes indicações: para Alberto: "Exmo. Sr. Turista Alberto Silveira”. E para Rute: "Poetisa Rute Silveira”.

Rute questiona:

- Poetisa! - disse a menina, sem entender.

- Poetisa - confirmou o tio. Pois você não gosta de coisas maravilhosas e impossíveis- de sereias, de fadas, de anjos...?

A descoberta recente desse texto foi uma agradável surpresa. Como narrativa, revela uma ficcionista hábil em criar diálogos e mudanças de situação. O encaixe de informes geográficos e históricos harmoniza-se com a apresentação das cenas familiares. Seria muito interessante, se pudéssemos saber alguma coisa sobre a utilização desse "manual didático", na ocasião em que foi adotado. Como teria sido recebido pelos leitores? E pelos mestres? Ainda está por ser feita uma pesquisa que nos traga essas respostas...

\title{
1939 / 1940 Olhinhos de gato
}

Olhinhos de gato, memórias de infância, foi obra publicada em capítulos, na revista portuguesa Ocidente, em 1939 / 1940. Anos depois, deslocou-se o enfoque relativo ao público-alvo. O livro de memórias de infância teve seus capítulos reunidos, para compor um volume, saltando da revista especializada para a coleção destinada a jovens leitores, em lançamento da Editora Moderna, São Paulo, em 1983.

Mais uma vez, revela-se o talento da ficcionista, numa narrativa autobiográfica marcada pela poeticidade. O relato é feito em primeira pessoa verbal, sendo a realidade observada pelos olhos de Olhinhos de gato, a narradora-personagem. Introvertida, solitária e contemplativa, ela não deixa de observar com atenção o mundo a sua volta, registrando o ruído dos vendedores e das brincadeiras infantis. Vez ou outra, citam-se pregões, parlendas ou cantigas:

\author{
Hoje é Sábado \\ de Aleluia \\ peixe no prato \\ farinha na cuia! [ oc. 110]
}

Ao longo do livro, encaixam-se narrativas dentro da narrativa, isto é, trechos que, isoladamente, poderiam ser considerados crônicas ou pequenos contos, com feitos mágicos que os aproximam de histórias de fada ou contos maravilhosos: 
Naquela casa mágica, uma noite, dentro de um armário, começaram a cantar criaturas secretas. /.../ Ela estava sentada no tapete: foi andando de joelhos para espiar por baixo do móvel. Não viu nada. Mas não achou muito espantoso. Aquela casa era assim mesmo. Dava-se corda no armário e ele falava e cantava sozinho. [ oc. p 80]

Seria possível debater a qual leitor essa obra estaria efetivamente dirigida. À criança ou ao adulto? Mais que contar uma história, a obra sugere reflexões sobre a vida, a morte, o relacionamento humano. Para ser lida por crianças, necessária se faz a mediação de um mestre hábil e sensível que oriente o jovem leitor em seu primeiro contato com a obra.

\section{Rui, pequena história de uma grande vida}

Em 1949, apareceu Rui, pequena história de uma grande vida, em edição comemorativa do centenário de Rui Barbosa, oferecido como presente aos alunos que concluíram naquele ano o "curso primário"- na época, término do ensino obrigatório.

A elaboração de algumas dessas obras decorreu de encomenda, função aceita pela mãe de família permanentemente preocupada em buscar recursos para a subsistência. Foi o caso deste livro, destinado a fazer parte dos festejos do centenário do orador e político.

O livro intercala o texto da autora e citações do homenageado, organizando-se em vinte e oito capítulos, precedidos de nota biográfica. A trajetória de Rui Barbosa é apresentada, a partir do cenário baiano- tema do capítulo 1- suas igrejas, seus conventos, e suas bibliotecas. A vida do herói acompanha a história do país, mesclando tom narrativo e fatos documentados, buscando levar os leitores a compreender o envolvimento de um grande homem com sua pátria. $O$ capítulo final comenta $o$ desaparecimento de Rui Barbosa, dando pistas de sua permanência metafórica:

Sua casa, serena, sabe que o dono viaja por países sem fim: foi sempre seu destino procurar o Futuro... o Futuro... - prosseguir para longe, atrás de um clarão que aparecia e desaparecia, mas hoje, certamente, brilha a seus olhos, imóvel e imortal.

[ oc. p 95]

\section{Giroflê, giroflá}

Giroflé, giroflá, prosa poética com pinceladas autobiográficas, foi destinado a crianças pela própria autora, tendo sido publicado pela Editora Civilização brasileira, 
em 1956. Mais recentemente, a Editora Moderna passou a reeditar a obra em prosa de Cecíla, em coleção paradidática destinada a jovens, sendo o texto literário acompanhado de um suplemento de leitura ou roteiro de estudo. A obra foi publicada nessa coleção em 1981.

O livro abre-se com a cantiga homônima ao título, sendo seguido de sete textos longos, em prosa poética, com alternância de trechos descritivos e trechos reflexivos. A prosa poética de Giroflê, giroflá emprega recursos próximos aos da poesia. Imagens, efeitos rítmicos, paralelismos, figuras criam efeitos expressivos e ampliam o poder de sugestão do trecho, como ilustram os exemplos abaixo:

\footnotetext{
Naquele tempo, não falávamos com esta facilidade de agora: nossos pensamentos eram ainda, como estas águas, de emaranhadas teias, com luz e limo, diamantes rápidos e viscosos vagares de pântano. [ o.c. p 25]

Isto é o Reino da Solidão. A linguagem, impossível: cada objeto possui a sua, com seus símbolos e privilégios. E o mesmo sol acorda as cintilações que a aranha gerou sem saber; descobre as inúmeras, imperceptíveis escamas da água que parecia completamente lisa; revela o fulgor de cada grão de areia, de cada poro da pedra; desvenda o sutil, imponderável esmalte de que estão recamados os minuciosos mantos das borboletas. [ o.c. 36]
}

\section{Ou isto ou aquilo}

Ou isto ou aquilo, poemas, de 1964, pela Editora Giroflê- reeditado depois pelas editoras Melhoramentos( $1972-2^{\mathrm{a}}$ ed.) e Civilização Brasileira ( $5^{\mathrm{a}} \mathrm{ed} .1981$ ), dentre outras, contou com ilustrações de diferentes artistas, conforme estudo de Luís Camargo, evidenciando convergências e/ou contradições entre texto verbal e visual, nas várias edições.

É a mais conhecida obra para crianças de Cecília Meireles, sucesso editorial que encanta leitores de todas as idades. Trata-se de obra bastante analisada, razão pela qual não será comentada aqui. Os poemas apresentam uma aparente simplicidade de composição e de linguagem, resultado de cuidadosa elaboração, como ilustram os dois dísticos do poema sobre o dilema da escolha que dá título ao livro:

\footnotetext{
Ou guardo do dinheiro e não compro o doce

Ou compro o doce e gasto o dinheiro.

Ou isto ou aquilo: ou isto ou aquilo...

E vivo escolhendo o dia inteiro!
}

\section{Conclusão}

Independentemente da distinção entre a leitura "por obrigação" ou "por prazer", há uma semelhança comum a todas as obras: o estilo da poetisa, marcado pela elaboração formal, pelo tom poético, pelo ritmo envolvente, traços presentes com maior 
ou menor evidência em todo o conjunto. Daí a possibilidade de reaproveitamento de alguns textos, segundo critérios editoriais que levaram em conta a sua qualidade literária e não a sua destinação inicial a outro tipo de público. 